RP, smoking and presence of hypertension or diabetes. To compare qualitative variables, the test was used Chi-square or Fisher's test. To compare quantitative vs qualitative variables Student's T test was used. Significance was considered for those values with $\mathrm{p}<0.05$.

Results: Between May 2014 to December 2016 images of 406 patients were collected: 24 dSSc, 41 ISSc, 19 DM, 14 PM, 40 SLE, 39 PSS, 37 RA, 44 PRP and 145 controls. C $84.5 \%$ were women, the age of the sample were $51.32 \pm 15.21$ years. $28.9 \%$ had a history of smoking and $21.1 \%$ and $5.5 \%$ of hypertension or diabetes, respectively. Excluding the cases of dSSc, ISSc, PRP and the 145 controls, the presence of RP was observed in $18 / 152(11.84 \%)$. The afferent, efferent, apical diameter And capillary was $26.01 \pm 19.01 ; 31.93 \pm 24.51$ um; $37.95 \pm 36.67$ um and $82.68 \pm 58.10$ um respectively. The most frequent qualitative finding were tortuosities. The control group showed no difference in the presence of hypertension or diabetes except in patients with PM. We also observed more women in SLE and PSS patients vs control group and greater presence of digital ulcers in ISSc, dSSc, SLE and DM. Only the ISSc presented differences in the presence of tortuosities with respect to the control group.

Conclusions: Except in the ISSc no differences were observed in the presence of tortuosities with the rest of groups and its presence may not be relevant in different diseases.

Disclosure of Interest: None declared

DOI: 10.1136/annrheumdis-2017-eular.4408

\section{SAT0636 ULTRASONOGRAPHY DEFINITIONS FOR SYNOVITIS GRADING IN CHILDREN: THE OMERACT PEDIATRIC ULTRASOUND TASK FORCE}

J. Vojinovic $^{1}$, S. Magni-Manzoni ${ }^{2}$, P. Collado ${ }^{3}$, D. Windschall ${ }^{4}$, V. Ravagnani ${ }^{5}$, C. Hernandez-Diaz ${ }^{6}$, J.C. Nieto Gonzales ${ }^{7}$, C. Malattia ${ }^{8}$, N. Tzaribachev ${ }^{9}$, G. Susic ${ }^{10}$, N. Damjanov ${ }^{11}$, S. Guillaume Czitrom ${ }^{12}$, T. Herlin $^{13}$, S. Lanni ${ }^{8}$, G. Bruyn ${ }^{14}$, A. lagnocco ${ }^{15}$, L. Terslev ${ }^{16}$, M.-A. D'Agostino ${ }^{17}$, E. Naredo ${ }^{7}$. ${ }^{1}$ Clinical Centre, Medical Faculty, University of Nis, Nis, Serbia; ${ }^{2}$ Ospedale Pediatrico Bambino Gesu, Rome, Italy; ${ }^{3}$ Hospital Universitario Severo Ochoa, Madrid, Spain; ${ }^{4}$ Department of Pediatrics, Asklepios Hospital Weissenfels, Weissenfels, Germany; ${ }^{5}$ Department of Medicine, University of Verona, Verona, Italy; ${ }^{6}$ Instituto Nacional de Rehabilitación, Mexico City, Mexico; ${ }^{7}$ Department of Rheumatology, Hospital General Universitario Gregorio Marañón and Complutense University, Madrid, Spain; ${ }^{8}$ IRCCS Istituto Giannina Gaslini, Genova, Italy; ${ }^{9}$ PRI - Pediatric Rheumatology Research Institute, Bad Bramstedt, Germany; ${ }^{10}$ Institute for Rheumatology; ${ }^{11}$ Institute for Rheumatology, University of Belgrade, Belgrade, Serbia; ${ }^{12}$ Rhumatologie Pédiatrique, CHU Bicêtre, le Kremlin-Bicêtre, France; ${ }^{13}$ Department of Pediatrics, Aarhus University Hospital Skejby, Aarhus N, Denmark; ${ }^{14}$ Department of Rheumatology, MC Group, Lelystad, Netherlands; ${ }^{15}$ Università degli Studi di Torino, Turin, Italy;

${ }^{16}$ Department of Rheumatology, University of Copenhagen, Copenhagen, Denmark; ${ }^{17}$ APHP, Hôpital Ambroise Paré, Rheumatology Department, UFR Simone Veil, Versailles-Saint-Quentin University, Saint-Quentin en Yvelines, France

Background: Ultrasound (US) was found to have face and content validity for detecting synovitis in juvenile idiopathic arthritis (JIA) with higher sensitivity than clinical examination. In order to test validity and improve the applicability of US in JIA, the OMERACT US pediatric subtask force recently published preliminary definitions for the sonographic features of synovitis in children.

\begin{tabular}{|c|c|c|c|c|c|c|c|c|}
\hline \multicolumn{5}{|c|}{ B-mode (GS) } & \multicolumn{4}{|c|}{ color power/Doppler (PD) } \\
\hline 0 & \multicolumn{4}{|c|}{$\begin{array}{l}\text { No signs of synovial effusion or synovial } \\
\text { hypertrophy (ie. no joint recess } \\
\text { enlargement capsular distension). }\end{array}$} & \multicolumn{4}{|c|}{$\begin{array}{l}\text { Absence of color/power Doppler signal within } \\
\text { synovial hypertrophy with or without detection } \\
\text { of nomal physiological Doppler signals. }\end{array}$} \\
\hline 1 & \multicolumn{4}{|c|}{$\begin{array}{l}\text { Synovial effusion and or synovial } \\
\text { hypertrophy that leads to a mild change of } \\
\text { the joint recess appearance (ie. mild joint } \\
\text { recess enlargement/capsular distension). }\end{array}$} & \multicolumn{4}{|c|}{$\begin{array}{l}\text { Detection of up to } 3 \text { single Doppler signals } \\
\text { within the area of synovial hypertrophy with or } \\
\text { without normal physiological Doppler signal s. }\end{array}$} \\
\hline 2 & \multicolumn{4}{|c|}{$\begin{array}{l}\text { Synovial effusion and or synovial } \\
\text { hypertrophy that leads to a moderate } \\
\text { change of the joint recess appearance (is. } \\
\text { moderate joint recess enlargementicapsular } \\
\text { distension). }\end{array}$} & \multicolumn{4}{|c|}{$\begin{array}{l}\text { Detection of more than } 3 \text { single Doppler signals } \\
\text { but less than } 30 \% \text { of the area of synovial. } \\
\text { hypertrophy with or without nomal. } \\
\text { physi ological Doppler signal s. }\end{array}$} \\
\hline 3 & \multicolumn{4}{|c|}{$\begin{array}{l}\text { Synovial effusion and or synovial } \\
\text { hypertrophy that leads to a severe change } \\
\text { of the joint recess appearance (ie. severe } \\
\text { joint recess enlargement' capsular } \\
\text { distension). }\end{array}$} & \multicolumn{4}{|c|}{$\begin{array}{l}\text { Detection of Doppler signals at more than } 30 \% \\
\text { of tha area of synovial hypertrophy with or } \\
\text { without normal physiological Doppler signals }\end{array}$} \\
\hline & \multicolumn{4}{|c|}{ Intra-observer } & \multicolumn{4}{|c|}{ Inter-observer } \\
\hline \multirow[t]{2}{*}{ Grade } & \multicolumn{2}{|c|}{$\begin{array}{l}\text { Percentage } \\
\text { agreement }\end{array}$} & & $\begin{array}{l}\text { Kap pa } \\
\text { Cohen }\end{array}$ & \multicolumn{2}{|c|}{$\begin{array}{l}\text { Percentage } \\
\text { agreement }\end{array}$} & \multicolumn{2}{|c|}{$\begin{array}{l}\text { leappa } \\
\text { PABAK }\end{array}$} \\
\hline & GS & PD & & PD & GS & PD & GS & PD \\
\hline 0 & 100 & 94 & & 0.83 & 100 & 100 & 1.0 & 1.0 \\
\hline 1 & so & 83 & 0.5 & 0.5 & 60 & 50 & 0.47 & 0.33 \\
\hline 2 & 89 & 83 & 0.7 & 0.67 & 50 & 71 & 0.5 & 0.62 \\
\hline 3 & 81 & 92 & 0.92 & 0.8 & 86 & 71 & 0.81 & 0.71 \\
\hline
\end{tabular}

Figure 1. Synovitis grading definitions in children and inter- and intra-observer reliability in Bmode (GS) and color power/Doppler (PD).
Objectives: Aim of this study was to confirm and improve B-mode and color power/Doppler (PD) US definitions for synovial components and grading in children, by using an image and patient based exercise.

Methods: The definitions were confirmed and modified in a multi-step process. In the 1st step, definitions were developed in multi-round Delphi web based consensus process were $\geq 80 \%$ of participants would need to reach $\geq 80 \%$ of agreement on a Likert scale from 1-5 (1 strongly disagree, 2 disagree, 3 neutral, 4 agree, 5 strongly agree). In the 2nd step, in a face to face meeting, a subgroup of these experts revised the definitions for final wording and performed intra- and inter-observer reliability exercise study in JIA patients as the final 3rd phase of the process. The definitions were tested in four joints (wrist, 2nd MCP, knee and ankle) of JIA patients divided in four age groups following standardized image acquisition and machine setting protocol. Statistics program $\mathrm{R}$ (version 3.3.0) was used for the statistical analyses. For intra-rater agreement Cohen kappa and for inter-rater agreement prevalence and bias adjusted kappa (PABAK) were calculated if needed.

Results: Reliability exercise included $20 \mathrm{JIA}$ patients (distributed in equal numbers by age groups), 14 observers, 4 joints/observer, 3 observers/joint, 360 intra- and 360 inter-observer tests. A 0-3 semi-quantitative B-mode and color power/Doppler US definitions for synovial components and grading, were agreed (presented in Figure 1).

Conclusions: The proposed synovitis grading for children showed to be reliable why the next step should be to test sensitivity to change in order to possibly be used as an outcome tool in JIA.

Disclosure of Interest: None declared

DOI: 10.1136/annrheumdis-2017-eular.6199

\section{SAT0637 ULTRASOUND ASSESSMENT OF SKIN THICKNESS IN SYSTEMIC SCLEROSIS PATIENTS: CORRELATION WITH CLINICAL FEATURES}

J. Sousa-Neves $^{1}{ }^{1}$, M. Cerqueira ${ }^{1}$, D. Santos-Faria ${ }^{1}$, J. Leite Silva ${ }^{1}$, A. Raposo ${ }^{2}$, C. Afonso ${ }^{1}$, F. Teixeira ${ }^{1} .{ }^{1}$ Rheumatology, Hospital Conde de Bertiandos, ULSAM, Ponte de Lima; ${ }^{2}$ Rheumatology, Centro Hospitalar Trás-os-Montes e Alto Douro, Vila Real, Portugal

Background: Although modified Rodnan skin score (mRSS) is the most widely used measure for assessment of skin involvement in Systemic Sclerosis (SSc), ultrasound (US) of skin thickness seems to be a promising complementary tool. (1)

Objectives: To compare skin thickness measured by US of a defined anatomical point between SSc patients and age and sex matched controls. To compare, among patients, US measurements of skin thickness with local and total mRSS and other specific clinical variables.

Methods: Forty-eight SSc patients and 45 age and sex matched controls were evaluated in a cross-sectional study at our Rheumatology Unit. SSc patients had a mean age of $56.98 \pm 12.73$ years and mean disease duration of $9.77 \pm 6.12$ years; 42 patients had limited cutaneous disease. Regarding US assessment, skin thickness was arbitrarily defined as thickness of epidermis, dermis and subcutaneous tissue, in millimetres, measured at the 2nd finger of both hands of each subject on the dorsal aspect of the proximal phalange. Examination was performed with a $15 \mathrm{MHz}$ linear probe of a General Electric LOGIQ S8 US. For comparison between groups, mean skin thickness (mST) of combined right and left side was used. Patients' local and total mRSS were also assessed. Hand mobility in SSc (HAMIS) was calculated to evaluate functional disability and SSc Severity Scale (SScSS) to estimate activity and damage. Additional data was also collected from patients' clinical charts. Statistical analysis included Mann-Whitney U-test, Kruskal-Wallis and Spearman correlation coefficient test. Statistical significance was defined as $\mathrm{P}$ value $<0.05$.

Results: SSc patients showed higher mST (3.17 mm [2.56 to 3.58]) (median [interquartile range]) compared with controls ( $1.89 \mathrm{~mm}$ [1.55 to 2.08]) ( $\mathrm{p}<0.001)$. Among SSc group, skin thickness measured by US of both 2nd fingers of each patient strongly correlated with local mRSS assessed by palpation (Spearman's rho $=0.698, p<0.001$ and rho $=0.645, p<0.001$ for right and left sides, respectively). US mST was also correlated with total mRSS ( $r h o=0.568, p<0.001$ ), HAMIS (rho $=0.520, p<0.001)$ and SScSS $(r h o=0.524, p<0.001)$. A higher $\mathrm{mST}$ was found in patients clinically classified with oedematous phase $(p<0.001)$ and in diffuse cutaneous subtype $(p=0.039)$. A mild association was observed for patients with digital ulcers $(p=0.05)$. Age, gender, disease duration and the presence of calcinosis were not associated with US mST $(p>0.05)$.

Conclusions: US measurements of skin thickness of 2 nd fingers were significantly higher in SSc patients compared with age and sex matched controls. US mST strongly correlated with local and total mRSS and was significantly higher in the presence of oedema, digital ulcers and in patients with diffuse subset. US mST also reflected functional disability and damage.

References:

[1] Hesselstrand R et al. High-frequency ultrasound of skin involvement in systemic sclerosis reflects oedema, extension and severity in early disease. Rheumatology (2008) 47 (1): 84-87.

Disclosure of Interest: None declared

DOI: 10.1136/annrheumdis-2017-eular.4541 